九州大学学術情報リポジトリ

Kyushu University Institutional Repository

\title{
Current Status of Insect Pests Attacking Green Bunching Onion in Central and Southern Vietnam
}

Ueno, Takatoshi

Faculty of Agriculture, Kyushu University

https://doi.org/10.5109/9242

出版情報：九州大学大学院農学研究院紀要. 51 (2)，pp.275-283，2006-10-27. Faculty of Agriculture, Kyushu University

バージョン :

権利関係 : 


\title{
Current Status of Insect Pests Attacking Green Bunching Onion in Central and Southern Vietnam
}

\author{
Takatoshi UENO* \\ Laboratory of Insect Natural Enemies, Division of Biological Control, Department of \\ Applied Genetics and Pest Management, Faculty of Agriculture, \\ Kyushu University, Fukuoka 812-8581, Japan \\ (Received June 29, 2006 and accepted July 24, 2006)
}

\begin{abstract}
Green bunching onion (or Welsh onion) Allium fistulosum is traditionally an important vegetable in Vietnam. The present study was undertaken to survey the current status of insect pests on green bunching onion in the country. Survey was conducted in conventional fields in central and southern Vietnam. The most widespread pest was Stone leek leafminer Liriomyza chinensis, which occurred all lowland sites investigated except Da Lat, a highland site in central Vietnam. Although insecticides were intensively applied, the percentage of the occurrence in green onion fields was 100\% in Bien Hoa, Hue, Huong An, and Quang Nam. In Dalat, L. huidobrensis instead was widely found in Allium fistulosum and A. cepa. Serious infestation by lepidopterans often occurred, and the main species was beet armyworm Spodoptera exigua, which was widely found in lowland areas. Infestation by $S$. exigua was heavier in summer than in spring. Damage by $S$. litura was observed in all localities. Helicoverpa armigra infested green bunching onion in Hue though it was rare. Thrips were rather a minor pest though it was abundant in Quang Nam. No pest aphids were confirmed. Taken together, management of leafminer and lepidopteran pests is crucial to stable production of marketable green bunching onions. Current problems associated with insect pest control in Vietnam are discussed, and the importance of IPM practices is emphasized. A series of color photographs of pests and the damage they can cause are presented to facilitate identification of the pest.
\end{abstract}

\section{INTRODUCTION}

Green onion or green bunching onion is produced from immature Allium cepa and from Allium fistulosum, the latter of which is commonly known as Japanese bunching types. Green onion is a perennial crop widely cultivated throughout the world, particularly in Asian countries, where it is grown as an annual (Larkcom, 1991; Davies, 1992). In Vietnam, green onion is an important seasoning vegetable, or flavoring herb, or a medical plant, which is of high value (Dan and Nhu, 1989).

As with the case for many vegetable crops, pest control or management is crucial to stable production of marketable green bunching onions. Chemical control, i.e. the use of synthetic pesticides, is currently the sole measure (except 'hand-picking') for controlling pests of green bunching onion in Vietnam, because synthetic pesticides can be relatively cheap and are easy to apply, and fast-acting. Despite the advantages of synthetic insecticides, the problems associated with their use have been well documented. These include the resurgence of pest populations, development of pesticide-resistance, and negative impacts on non-target organisms within and outside the crop system (Flint and van den Bosch, 1981; Denholm and Rowland, 1992; Dent, 2000). Limited information suggests that those problems can hold true for green onion production in Vietnam (Tran and Takagi, 2005a, b).

To solve the problems associated with exclusive chemical control, integrated pest management (IPM) uses a variety of techniques such as crop rotation,

\footnotetext{
* Corresponding author (E-mail: ueno@grt.kyushu-u.ac.jp)
}

tillage, biological and chemical controls, to manage crop pests (Pimentel, 1997; Dent, 2000). Knowledge of pests, e.g. identification, ecology, behavior, life history, population dynamics, is essential to this integrated approach (Flint and van den Bosch, 1981; Dent, 2000). Then the first step in an effective IPM program is properly identifying the pest. Incorrect identification could lead to the use of the wrong pesticide or improper timing of pesticide applications, and add unnecessary chemicals to the environment. Correct identification of the pest allows proper use of pesticides that are more effective and selective.

The current status of pests of green bunching onion, i.e. occurrence, abundance, species composition etc., is not fully understand in Vietnam, however. Thus, the present study was aimed to reveal the current status of insect pests of green onion in the country. For this purpose, general survey was conducted in conventional onion fields in several localities of central and southern Vietnam. Insect pests found during the survey are listed here. In addition, the physical features of insect pests and the type of damage they cause are shown together with photographs, which would be helpful for identification of pests. The problems and future subjects to practice IPM in green bunching onion are discussed.

\section{MATERIALS AND METHODS}

\section{Study sites}

Survey was conducted in spring (February $22^{\text {th }}$-March $7^{\text {th }}$ ) and summer (July 3rd-1 $7^{\text {th }}$ ), 2005. Study sites included Da Lat, Hue, Huong An, Quang Nam, and Bien Hoa. Da Lat is located at a central highland area, whereas Hue, Huong An and Quang Nam are located at 
lowland areas in central Vietnam. Bien Hoa is at southern Vientam, near Ho Chin Minh City.

All onion fields investigated in the present study were conventional fields. Farmers sprayed insecticides once or twice a week there. In central lowland areas, cartap was mostly the sole chemical used in surveyed onion fields. In Da Lat, farmers used a variety of chemicals, including cartap, BT, fenvalerate, etc. In Bien Hoa, cypermethrin, fenobucarb, phenthoate, profenofos, fenvalerate, cartap, etc. were applied, depending on farmers.

\section{Survey}

Survey was done by inspecting individual plants in the field. The entire plant was searched to locate insect pests. When scouting fields, each field was sampled at a minimum of four sites. Up to a total of 50 plants per field with 10-15 plants per inspection site were sampled. When an insect pest had been encountered, tentative identification was made and the species was recorded. Also, the stages of insects observed were checked. Specimens were brought back to the laboratory for exact identification when necessary. However, this was mostly not required because pest species diversity was very poor, and the majority of pests was well-known species and easy to identify. When foliage damage had been encountered, it was determined which pest species was responsible.

\section{THE RESULTS AND DISCUSSION}

\section{Occurrence and status of insect pests}

Among the lepidopterans detected during the survey, the following three species were of particular importance as onion pests: Beet armyworm Spodoptera exigua (Hübner), common cutworm Spodoptera litura (Fabricius), and corn earworm Helicoverpa armigra (Hübner) (Lepidoptera: Noctuidae) (Table 1). Among the three, $S$. exigua was the most frequent and damaging pest of Allium fistulosum in lowland areas (Table

Table 1. List of main pest insects confirmed during the survey

\begin{tabular}{lccccc}
\hline & \multicolumn{5}{c}{ Localities } \\
\cline { 2 - 6 } Species & Dalat & Hue & $\begin{array}{c}\text { Huong } \\
\text { An }\end{array}$ & $\begin{array}{c}\text { Quang } \\
\text { Nam }\end{array}$ & $\begin{array}{c}\text { Bien } \\
\text { Hoa }\end{array}$ \\
\hline Lepidoptera & & & & & \\
S. exigua & - & $\bigcirc$ & $\bigcirc$ & $\bigcirc$ & $\bigcirc$ \\
S. litura & $\bigcirc$ & $\bigcirc$ & $\bigcirc$ & - & $\bigcirc$ \\
H. armigra & - & $\bigcirc$ & - & - & - \\
Diptera & & & & & \\
L. chinensis & - & $\bigcirc$ & $\bigcirc$ & $\bigcirc$ & $\bigcirc$ \\
L. huidobrensis & $\bigcirc$ & - & - & - & - \\
Thysanoptera & & & & & \\
Thrips tabaci? & - & $\bigcirc$ & $\bigcirc$ & $\bigcirc$ & $\bigcirc$ \\
\hline
\end{tabular}

(O): Occurred widely and abundant suggesting chemical control did not work well. $\bigcirc$ : Confirmed but not abundant or rather rare suggesting chemical control worked well (or simply because the pests are rare in the locality). -: Not detected. See the text for other pest species found during the survey.
Table 2. The percentages of occurrence (per field) of two major pests infesting green bunching onion in conventional fields

\begin{tabular}{clcccc}
\hline & & \multicolumn{4}{c}{ Localities* } \\
\cline { 3 - 6 } $\begin{array}{c}\text { Pest } \\
\text { species }\end{array}$ & Seasons & Hue & $\begin{array}{c}\text { Huong } \\
\text { An }\end{array}$ & $\begin{array}{c}\text { Quang } \\
\text { Nam }\end{array}$ & $\begin{array}{c}\text { Bien } \\
\text { Hoa }\end{array}$ \\
\hline \multirow{2}{*}{ S. exigua } & Spring & $100(16)^{* *}$ & $23.5(17)$ & $33.3(6)$ & - \\
& Summer & $75.8(33)$ & $50.0(10)$ & - & $77.8(18)$ \\
& Spring & $100(16)$ & $100(17)$ & $100(6)$ & - \\
L. chinensi & Summer & $82.9(33)$ & $80.0(10)$ & - & $94.4(18)$
\end{tabular}

* Data collected in Dalat are not included because the two pest species have not been detected during the present survey.

** Data for S. exigua and L. chinensis were based on the presence of armyworm larvae and damage made by leafmining larvae, respectively. The number of fields surveyed is indicated in parenthesis. -: Not surveyed.

2). In Dalat, $S$. litura was the major lepidopteran pest, and $S$. exigua was not found there at least during the survey. The developmental stages observed were from eggs to pupae, and adult moths were not detected probably because they are inactive during daytime. Corn earworm was widely found on several crops in South Vietnam but it was rather rare on green bunching onion. Corn earworm was found attacking green bunching onion in Hue and Huong An during the spring survey but not detected in summer. The damage was not serious because the earworm was not abundant. One species of a looper was found on $A$. cepa in Dalat, but the identification was not made because it was legally impossible to return the caterpillars to Japan for rearing to the adult moth. The looper species was rare, and only two caterpillars were found during the survey in Dalat. It appears not to be a serious pest at least in conventional fields. Acrolepiopsis sapporensis (Matsumura), a widespread lepidopteran pest of green onions in Asia, Europe and North America, was not discovered in the present survey.

Two species of dipterans were found: Stone leek leafminer Liriomyza chinensis (Kato) and pea leafminer L. huldobrensis huidobrensis (Blanchard) (Table 1). The former has been known as a major pest of green bunching onion in many Asian countries including Vietnam and Japan (e.g. Shiao, 2004; Tokumaru, 2006; Tran et al., 2006). The latter was first to be found to infest $A$. fistulosum and $A$. cepa in Vietnam. While L. chinensis occurred in all lowland locations surveyed, L. huidobrensis was recorded only from Dalat, a highland area (Tables 1 and 2). In Dalat, 100 percent of all leafminer flies attacking $A$. fistulosum and $A$. cepa were L. huidobrensis. In contrast, more than 99 percent of leafminer flies on $A$. fistulosum were L. chinensis in lowland areas. In Hue and Huong An, damage caused by unknown serpentine leafminers was found though it was extremely rare. The species is most probably L. sativae, which is very abundant and attacks a variety of vegetable crops there (Tran et al., 2006).

In all localities, regardless of the seasons, all the 
developmental stages of $L$. chinensis were observed, i.e. adults, young and old larvae, and pupae, indicating that this pest continuously occurred and repeated the generations at least from spring to summer. Likewise, all the developmental stages were found for $L$. huidobrensis in Dalat. Although infestation levels varied between fields and locations for both leafminer species, they were commonly abundant, and damage was extensive for some green onion fields (Table 2), demonstrating that $L$. chinensis and L. huidobrensis were the most serious leafminers of green bunching onion in Central and South Vietnam. In Dalat, L. huidobrensis commonly infested spinach, celery, Chinese cabbage and paprika etc., indicating that this was the most important leafminer pest there.

Damage by thrips was occasionally found though adult thrips were rarely encountered except in Quang Nam (Table 1). The species could not be determined but it could be Thrips tabaci (Lindeman) (Thysanoptera: Thripidae), a worldwide pest of onion (Lewis, 1973; Waterhouse, 1987). Thrips puncture the leaves or stems and suck up the exuding sap. This feeding produces silvery-white, mottled lesions or whitish blotches on the leaf surface (Fig. 1). It is generally known that damage from thrips is most serious during hot, dry seasons. In most cases, thrips are not a problem in the rainy season probably because the rainfall washes tiny insects away from the plant.

Aphids can be important onion pests in temperate region in Asia. However, no aphid colony was found during the survey; I only found single winged individuals in some fields, and they were not attacking onion. At least in spring and summer, they were not serious pests of green bunching onion in Central and South Vietnam. Also I did not notify the presence of onion maggot Hylemya (= Delia) antiqua (Meigen) (Diptera: Anthomyiidae), a widespread serious pest of onion in the world. Both aphids and onion maggot are rather pests occurred in cool or temperate regions, and may therefore be lacking or rare in central and southern Vietnam.

\section{Leafmining pests}

Unlike other pest Liriomyza spp., stone leek leafminer L. chinensis is host-specific; it attacks only Allium spp. This leafminer originates in Asia (but see Martinez, 1982), and has become a prominent pest in green bunching onion in recent years. The body color of adult flies is dull pale yellow and matting grey (Fig. 2), which contrasts with bright yellow and glossy black colored Liriomyza species, such as L. sativae, L. trifolli and L. huidobrensis. It is thus easy to distinguish stone leek leafminer from other common Liriomyza pests.

Liriomyza huidobrensis is known as a highly polyphagous species capable of inflicting severe damage to crops (Parrella and Bethke, 1984; Parrella, 1987). It attacks a variety of crop and ornamental crops scattered among 15 plant families, including Liliaceae (Spencer, 1973, 1990). To my knowledge, Allium fistulosum has rarely been recorded as a host plant of $L$. huidobrensis so far. This leafminer is thought to be indigenous to cool, highland areas of South America but is now established in many countries outside South America, including Vietnam (Parrella, 1987; Spencer, 1992).

Adult L. huidobrensis can be distinguished from other common species of Liriomyza, i.e. L. sativae and L. trifolii, by overall dark color and the darkened legs (they are yellow in L. sativae and L. trifolii) (Fig. 3), and the male genitalia (see Spencer 1973). Further, $L$. huidobrensis larvae frequently mine along the midribs of leaves, and late instars are frequently found mining the lower surfaces of leaves or within petioles (This is not the case when it attacks onion. See below). This mining behavior is distinctly different from the serpentine mines of $L$. sativae and L. trifolii on upper leaf surfaces. As with the case for $L$. sativae and $L$. trifolii, L. huidobrensis often outbreaks in conventional fields due to insecticide resistance.

Liriomyza chinensis and L. huidobrensis have similar life histories. Females puncture leaves to feed on plant sap and lay eggs within the leaf tissue. Importantly, adult feeding punctures of L. chinensis
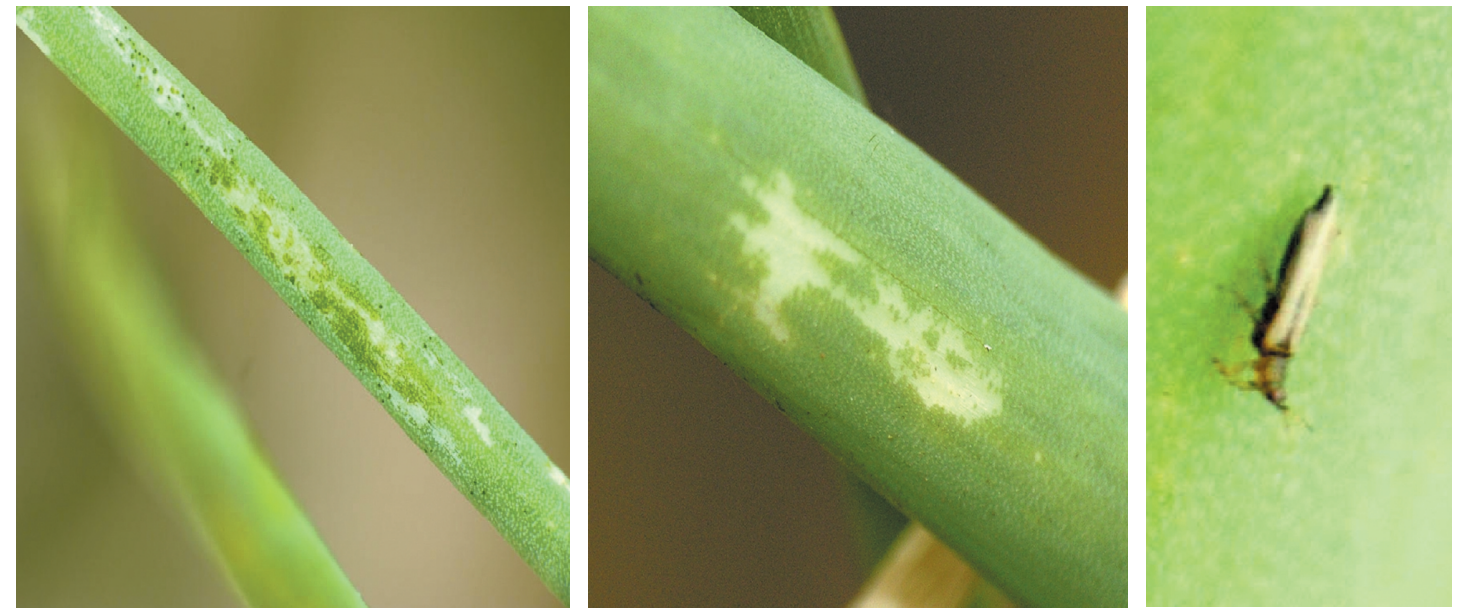

Fig. 1. Thrips (probably Thrips tabaci) attacking onion leaf and the damage. Photographs were taken at Quang Nam. 

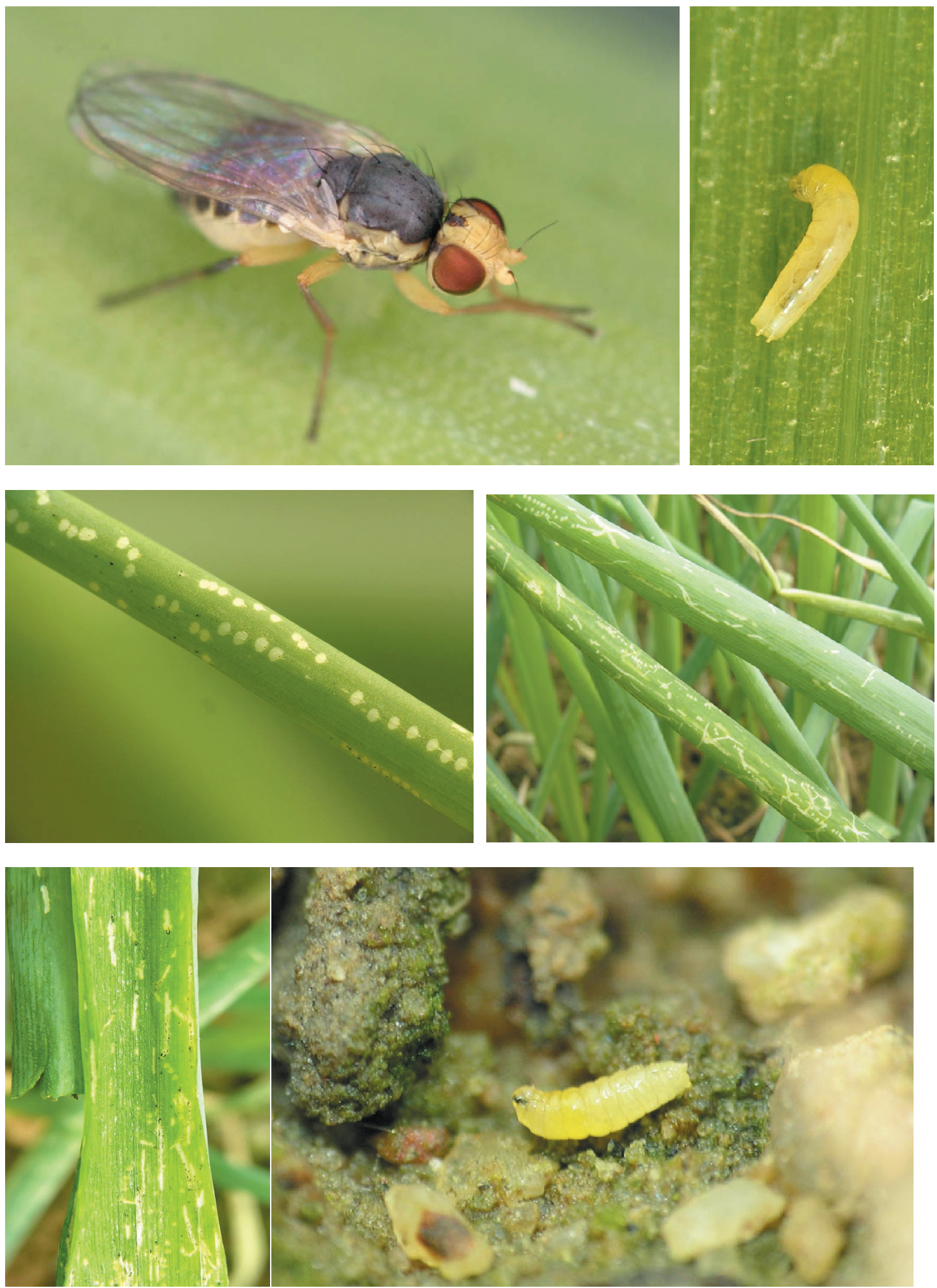

Fig. 2. Stone leek leafminer Liriomyza chinensis (above left: adult female, above right: mature larva within an onion leaf, middle leaf: adult feeding punctures made on the leaf, middle right: leaf mines, below left: larval mines inside leaf, below right: mature larva emerged from leaf, seeking pupation site in the soil.). Photographs were taken at Houng An. 

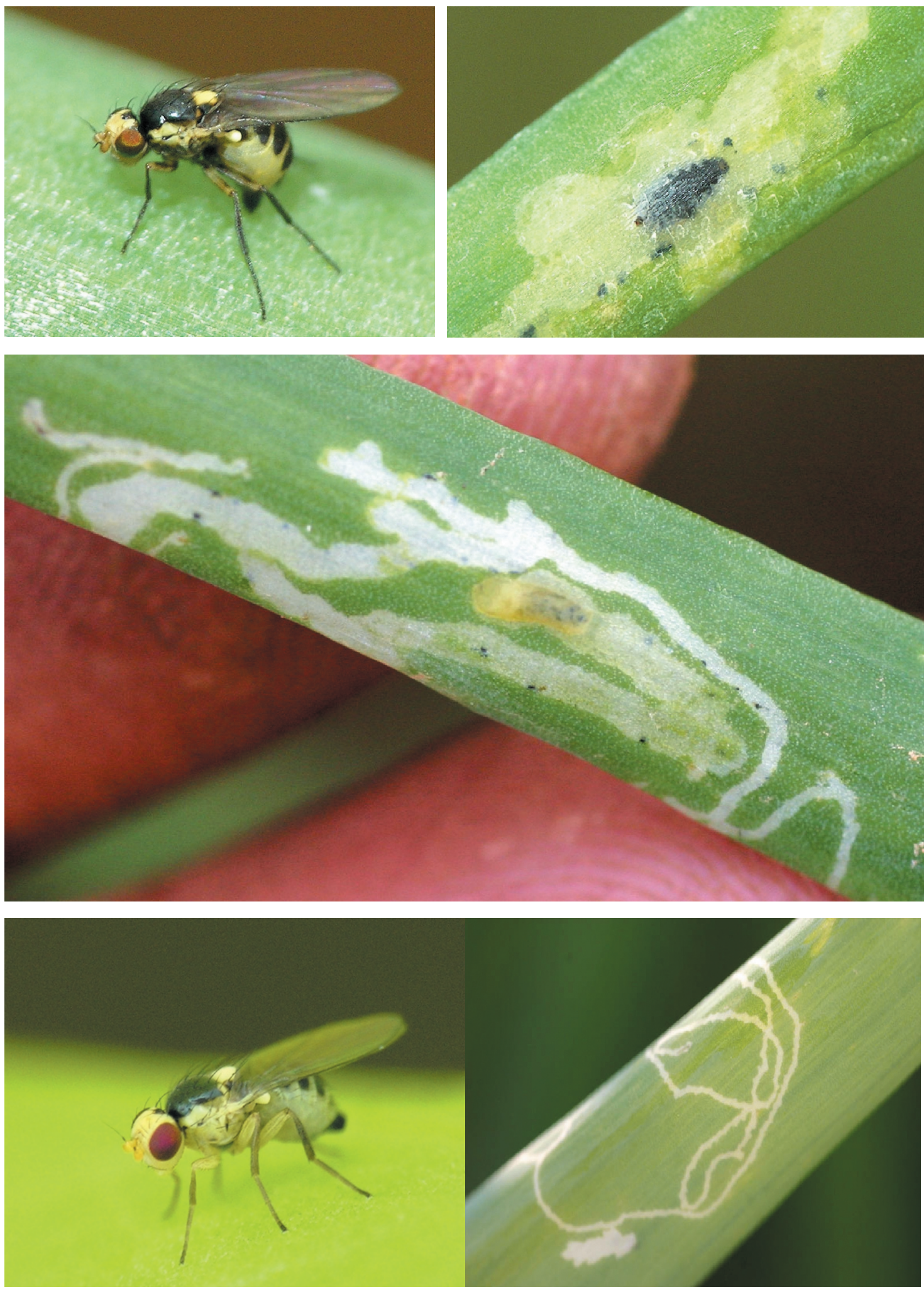

Fig. 3. Pea leafminer Liriomyza huidobrensis (above left: adult female ovipositing, above right: pupa just below the outer surface of onion leaf, middle: mature larva and the mine, below left: adult $L$. sativae, below right: larval mine probably made by $L$. sativae.). Photographs of $L$. huidobrensis and $L$. sativae were taken at Dalat and Hue, respectively. 

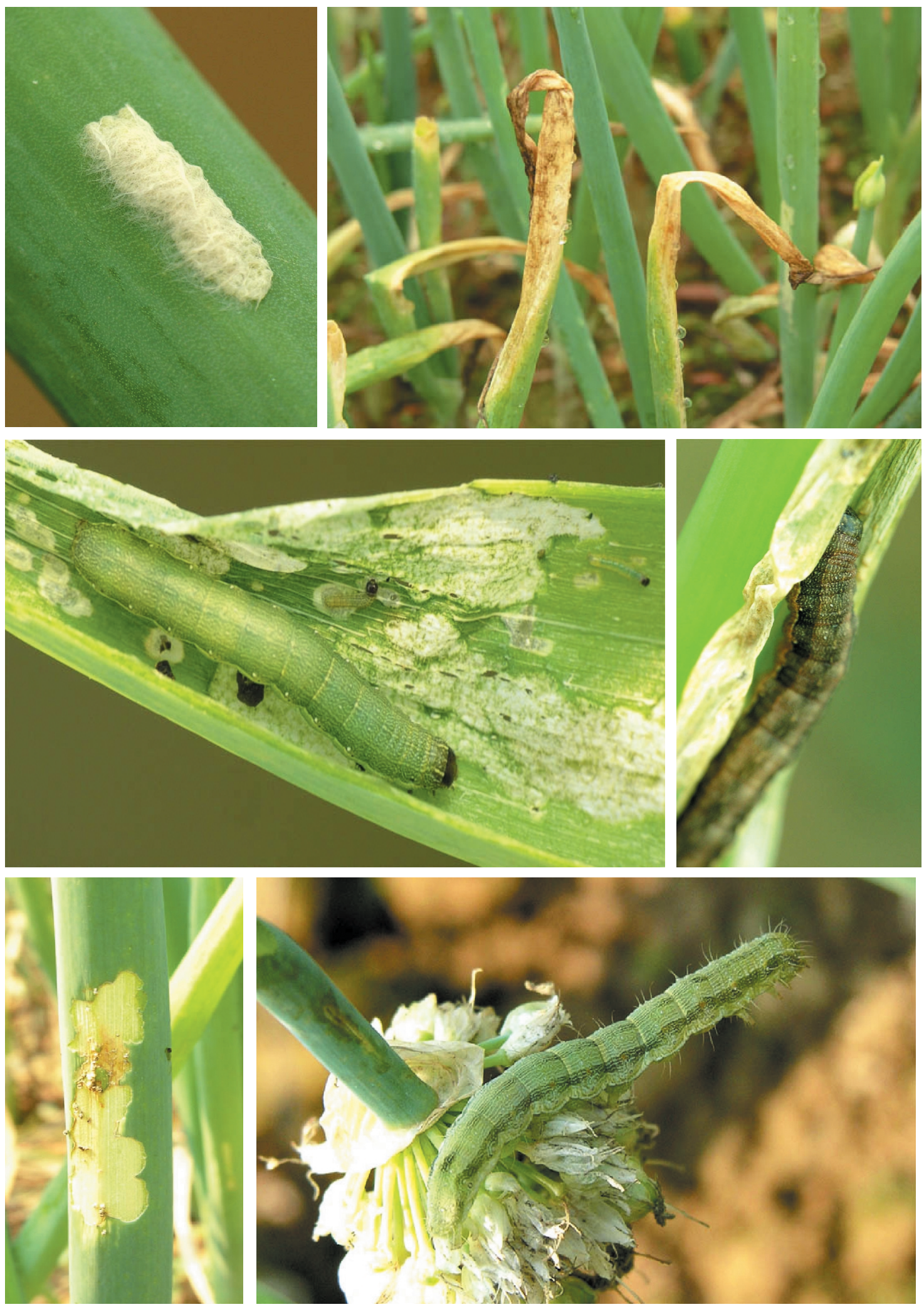

Fig. 4. The beet armyworm Spodoptera exigua (above left: egg mass, above right: damage caused by the armyworm, middle left: larvae with typical coloration inside onion leaf, middle right: larva with brown coloration, below left: damage made by $S$. litura, below right: Helicoverpa armigra larva.). Photographs were taken at Hue. 
form a longitudinal line (Fig. 2) whereas those of $L$. huidobrensis are sparsely and singly distributed on the onion leaves. Longitudinal lines of L. chinensis punctures are visibly conspicuous. By checking the presence of the characteristic feeding punctures on onion leaves, it is easy to recognize the occurrence of $L$. chinensis in the onion field.

Larvae feed between the leaf surfaces, creating a winding tunnel referred as to "mine." However, in $L$. chinensis, mature larvae leave the mine, and drop to the ground to pupate (Fig. 2) whereas mature larvae of L. huidobrensis remain in the mine where they pupate (Fig. 3). Also, an important difference is the type of mine. The latter makes a continuous, meandering mine (Fig. 3), whereas mines of the former are rather straight and visible part of mines are short and interrupted (Fig. 2). Mine patterns of $L$. chinensis are due to the fact that larvae alternately mine the outer and inner surfaces of onion leaves (Fig. 2). Mature larvae of L. chinensis are often found within onion leaves (Fig. 2). Body coloration of $L$. huidobrensis larvae are cream or pale yellow, whereas L. trifolii maggots are bright yellow. Although I did not found $L$. trifolii attacking green bunching onion during my survey, it is likely that the latter is a leafminer pest in some onion fields in Vietnam. The adult feeding punctures and mines are very similar, and hence are not used for distinguishing the two. However, tentative field identifications may be made on the basis of color of the larval body, and the presence of pupae in leaves (the latter pupates in the soil).

\section{Lepidopteran pests}

Spodoptera litura is a destructive pest of subtropical and tropical agriculture in Asia (Capinera, 2001). Spodopter litura can also be a serious pest of glasshouse crops or summer/autumn crops in temperate regions because it is a strong flier and can disperse long distances from warm to temperate areas. It attacks a wide range of plants. Many populations are extremely resistant to pesticides. Eggs are laid in clusters, on plants and other surfaces such as pots, nets or glasshouse structures. The female moth covers the egg masses with light brown hairs and scales. Larvae are dark in color with yellow bands along their backs and sides of their bodies. Mature larvae pupate in the soil. The feeding damage is different from that by the beet armyworm. Young and middle instars feed on the surface of onion leaves, leaving a typical feeding mark (Fig. 4).

The beet armyworm is native to Southeast Asia but now it is a worldwide pest (Capinera, 2001). It is a regular and serious pest of green bunching onion in Japan (e.g. Wakamura and Takai, 1992). Overall abundance is reduced in winter (Tingle and Mitchell 1977). Eggs are laid in clusters that are covered with a layer of whitish hairs and scales (Fig. 4). The larvae are pale green or yellow in color during the 1-4 instars (Fig. 4) but the final instar, i.e. $5^{\text {th }}$ instar, is variable in body coloration, ranging from green to brown and attaining a length of around $30 \mathrm{~mm}$ (Fig. 4). The head of larvae is black (Fig.
4). The larva sometimes has three longitudinal, light stripes. A small, black spot occurs on each side of the second segment behind the head. Mature caterpillars pupate in the soil. Spodoptera exigua and S. litura never cut off onion plants at or slightly below the surface of the soil. The beet armyworm is a polyphagous species, infesting a variety of vegetable and ornamental crops. Young larvae feed gregariously and skeletonize foliage (Fig. 4). As they mature, larvae become solitary and eat large irregular holes in foliage. Insecticide resistance is a major problem in management of the beet armyworm.

Corn earworm Helicoverpa armigra was occasionally found infesting green bunching onion (Fig. 4). Unlike the former two lepidopterans, females lay eggs singly on leaf, bud and flower. Freshly laid eggs are yellowish white but turn to dark-brown before hatching. The size of eggs is $0.4-0.6 \mathrm{~mm}$. The larvae of corn earworm is easily distinguished from the above two lepidopterans by the presence of conspicuous blackish hairs on the larval body (Fig. 4). The larvae range in color from pale green or pinkish to brown with three or fore dark stripes along their back. The head is yellow to green. Corn earworm is a generalist herbivore and attacks a wide variety of plants (more than 60 plant species in 27 families), including corn, tomato, pepper, bean. peanut, lettuce, cotton, cabbage, and a number of ornamental crops.

\section{Current problems of pest management}

There are a number of problems, which I notified, to be considered for effective and environmentally safe pest-management practices in Vietnam. In the present study, I surveyed in conventional fields of green bunching onion where farmers used insecticides once or twice a week. Damage made by lepidopterans and leafminers was nevertheless so excessive that chemical control evidently did not work well particularly in central lowland areas (Table 2; Ueno, unpublished). The primary reason could be the presence of highly resistant populations of the pests. In lowland areas of Central Vietnam, cartap was mostly the sole insecticide applied to control insect pests. Too much reliance to this chemical should cause emergence of resistance to this type of insecticides though cartap is generally thought to be a chemical tool against which resistance is difficult to evolve (e.g. Cheng and Kao, 1989). Cartap resistance is in fact known from some lepidopteran pests (e.g. Cheng, 1988; Siqueira et al., 2000). Cartap also may not be effective against Vietnamese L. chinensis (Tran et al., 2006). In addition to resistance, climate condition may adversely affect chemical control in lowland areas of Central Vietnam. Frequent rainfall in those areas may result in washing out insecticides applied before they will be effective. Further, many farmers did not know what they had used for pest control; they used cartap exclusively without understanding the effectiveness and advantage/disadvantage. Difficulty may lie in the fact that farmers in the areas are mostly poor, and education system is lacking. In any case, selection of effective 
insecticides, which should be cheap enough for farmers, should be required together with proper guidance for practicing effective pest control.

In Da Lat and Bien Hoa, where farmers often used a combination of different insecticides, damage by leafminers and lepidopterans appeared to be minimized in many fields. In those areas, farmers generally have a relatively rich knowledge about insecticides. However, it appeared to me that there was still a disparity among farmers in knowledge of chemicals. Economic loss due to pests greatly varied among green onion fields in Dalat and Bien Hoa, which might be resulted from different selection of chemicals that farmers had applied or might simply reflect differences in microclimate or soil conditions on pest abundance. Many subjects remain to be set to practice effective and reliable pest management practices.

\section{Management tactics}

Given the current situations in Vietnam, insecticides would be the primary method to manage insect pests in green bunching onion. However, unwise use of chemicals appears to cause resurgence of stone leek leafminer and beet armyworm as discussed above. It is important to select and use insecticides that are most effective to target pests but least harmful to beneficial organisms (and neutral organisms). Insecticides should also be used in the proper dose and only when necessary to prevent economic loss. Costs of insecticide application, prevailing crop market price and expected yield all must be considered when deciding to use an insecticide.

Pest management should not rely on a single control practice; IPM practices that integrate a variety of tactics should be used (Denholm and Rowland, 1992; Dent, 2000). IPM uses pest resistant or tolerant crop variety, and cultural, physical, mechanical, biological control, together with chemical control (e.g. Pimentel, 1997; Dent, 2000). Inclusion of different management tactics would be required in green onion production in Vietnam.

Conservation biological control can often be a useful, low-cost tactics (e.g. Barbosa, 1998; Dent, 2000). I made survey of insect natural enemies in Vietnam as well as pests and found that the abundance of natural enemies in general was rather poor in green bunching onion fields (Ueno, unpublished). This may be primarily because too much insecticide has been applied. In addition, it may be because stone leek leafminer and beet armyworm can host a few natural enemies or because green bunching onion is not attractive due to its characteristic odors, or because green onion fields are stressful environments for a number of natural enemies due to poor architecture of the onion or lack of refuge from direct sunlight.

Nevertheless I have found in Vietnam some significant natural enemies though it was evident that they did not always provide reliable control in most conventional onion fields (Ueno, unpublished). The importance and impact of natural enemies however should be assessed in non-sprayed fields because they must adversely be affected by unwise insecticide use. In fact, only one major parasitoid species was found attacking onion leafminers in conventional onion fields of Hue and Huong An (Tran et al., 2006; Ueno and Tran, unpublished) while a number of parasitoids emerge from the leafminer in non-sprayed onion fields in Japan (Tokumaru, 2006). Natural enemies may play an important role in suppressing pest populations in green bunching onion if proper insecticides that result in the least disruption to the natural enemy complex are used. Usefulness of conservation biological control should be considered in the production of green bunching onion.

Crop rotation is a cultural management approach that usually involves alternate use of host and non-host crops in a field to reduce pest abundance and damage when rotation is made on an area-wide scale (Dent, 2000). Crop rotation can be effective against insect pests with a limited host range and limited ability to move from one field to another. Rotation of different crop varieties can also be a useful approach. In Vietnam, a number of varieties of green bunching onion have been cultivated. They can be divided into two main types: multiplier and non-multiplier or splitting and single stalk types. These varieties considerably differ in attraction and tolerance to onion leafminer L. chinensis (Ueno, unpublished). High value, single stalk type is greatly susceptive whereas splitting stalk type, which represents local varieties, shows resistance. Alternate rotation of two main varieties on an area-wide scale may help reduce total leafminer populations in growing areas. IPM is a whole-season approach to managing pests.

In addition to the above-mentioned tactics, a traditional method can also be included as possible. All farmers knew noctuid caterpillars as an important pest of green bunching onion, and they often found and killed them by hand. The majority however did not recognize egg mass of Spodoptera. Farmers in central lowland areas of Vietnam did not use herbicides; they elaborately picked up weeds by hand. Then, it is recommended to find and kill Spodoptera egg mass as possible during the course. Early detection of the egg mass would help reduce the level of infestation by the armyworm.

While a number of synthetic insecticides are now sold in Vietnam, (seemingly) effective chemicals are expensive or are still not available for farmers in central Vietnam, where market price of onion is cheap. A limited chemical control options are thus available. Relying only on pesticides, especially the same chemical or chemical class, for pest control appears to cause pest resurgence in those areas. IPM approach with low-cost tactics is essential to solving the problems in central Vietnam as well as farmers' education. Extensive IPM studies in green onion production are required to combat the pest in a manner that results in minimal adverse impact to humans, non-target organisms and the environment.

\section{ACKNOWLEDGEMENTS}

First of all, I deeply appreciate Dr. Dang Hoa Tran at 
Hue University for his valuable and warmhearted help. I also greatly thank members of Hue University, Nong Lam University, and Plant Protection Department in Quang Nam and Dalat, who gave me hospitality during my stay in Vietnam. I finally thank Prof. M. Takagi at Kyushu University for giving me an opportunity to visit Vietnam for research purpose. This work was supported by a grant from the Ministry of Education, Sciences, Sports and Culture of Japan (No. 15208007).

\section{REFERENCES}

Barbosa, P. 1998 Conservation Biological Control. Academic Press, London

Capinera, J. L. 2001 Handbook of Vegetable Pests. Academic Press, San Diego

Martinez, M. 1982 Contribution a l'etude des Agromyzidae de France (Dipt.) (2e note). Liriomyza nietzkei Spencer et Liriomyza chinensis (Kato), deux especes d'importance economique presentes en France. Bull. Soc. Entomol. France, 87: 302-308

Cheng, E. Y. 1988 Problems of control of insecticide-resistant Plutella xylostella. Pestic. Sci., 23: 177-188

Cheng, E. Y. and C. H. Kao 1989 The resistance and chemical control of diamondback moth, Plutella xylostella. Proceedings of a Symposium on Insect Pest Management of Vegetable, 4: 15-27

Dan, N. V. and T. D. Nhu 1989 Medicinal Plants in Vietnam. World Health Organisation

Davies, D. 1992 Alliums. The Omamental Onions. Batsford, London

Denholm, I. and M. W. Rowland 1992 Tactics for managing pesticide resistance in arthropods: theory and practice. Annu. Rev. Entomol., 37: 91-112

Dent D. 2000 Insect Pest Management. 2nd Ed. Cabi Publishing, London

Flint, M. L. and R. van den Bosch 1981 Introduction to Integrated Pest Management. Plenum Press, NY

Larkcom, J. 1991 Oriental Vegetables. John Murray Publishers Ltd, London

Lewis, T. 1973 Thrips: their Biology, Ecology, and Economic Importance. Academic Press, London

Parrella, M. P. and J. A. Bethke 1984 Biological studies of Liriomyza huidobrensis (Diptera: Agromyzidae) on chrysanthemum, aster, and pea. J. Econ. Entomol., 77: 342-345

Parrella, J. 1987 Biology of Liriomyza. Annu. Rev. Entomol., 32: $201-204$

Pimentel, D. 1997 Techniques for Reducing Pesticide Use: Economic and Environmental Benefits. John Wiley and Sons, Chichester

Shiao, S. 2004 Morphological diagnosis of six Liriomyza species (Diptera : Agromyzidae) of quarantine importance in Taiwan. Appl. Entomol. Zool., 39: 27-39

Siqueira H. A. A., R. N. C. Guedes and M. C. Picanço 2000 Cartap resistance and synergism in populations of Tuta absoluta (Lep., Gelechiidae). J. Appl. Entomol., 124: 233-238

Spencer, K. A. 1973 Agromyzidae (Diptera) of Economic Importance. W. Junk B.V., The Hague.

Spencer, K. A. 1990 Host Specialization in the World Agromyzidae (Diptera). Kluwer Academic Publishers, Dordrecht

Spencer K. A. 1992 Flycatcher: Memoirs of an Amateur Entomologist. SPB Academic Publishing, The Hague

Tingle, F. C. and E. R. Mitchell 1977 Seasonal populations of armyworms and loopers at Hastings, Florida. Fl. Entomol., 60: $115-122$

Tokumaru, S. 2006 Hymenopterous parasitoids of Liriomyza chinensis Kato (Diptera: Agromyzidae) in Kyoto Prefecture. Jap. J. Appl. Entomol. Zool., 50: 63-65

Tran, D. H. and M. Takagi 2005a Developmental biology of Liriomyza chinensis (Diptera: Agromyzidae) on onion. J. Fac. Agric., Kyushu Univ., 50: 375-382

Tran, D. H. and M. Takagi 2005b Susceptibility of the stone leek leafminer Liriomyza chinensis (Diptera: Agromyzidae) to insecticides. J. Fac. Agric., Kyushu Univ., 50: 383-390

Tran, D. H., T. T. A. Tran, K. Konishi and M. Takagi 2006 Abundance of the parasitoid complex associated with Liriomyza spp. (Diptera: Agromyzidae) on vegetable crops in central and southern Vietnam. J. Fac. Agric., Kyushu Univ., 51: $115-120$

Wakamura, S. and M. Takai 1992 Control of the bet armyworm in open fields with sex pheromone. p. 115-125 in N.S Talekar (ed.) Diamondback Moth and other Crucifer Pests. Asian Research and Development Center, Taipei, Taiwan.

Waterhouse, D. F. 1987 Thrips tabaci Lindeman, Thysanoptera: Thripidae, onion thrips. In Biological Control: Pacific Prospects - Supplement 1. (Ed. D. F. Waterhouse and K. R. Norris). Inkata Press, Melbourne, Australia 